Dear Author,

Please, note that changes made to the HTML content will be added to the article before publication, but are not reflected in this PDF.

Note also that this file should not be used for submitting corrections. 


\section{AUTHOR QUERY FORM}

\begin{tabular}{|c|c|c|}
\hline 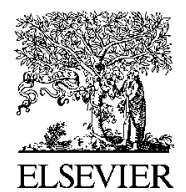 & Article Number: 1580 & $\begin{array}{l}\text { Please e-mail or fax your responses and any corrections to: } \\
\text { E-mail: corrections.esch@elsevier.thomsondigital.com } \\
\text { Fax: }+35361709272\end{array}$ \\
\hline
\end{tabular}

Dear Author,

Please check your proof carefully and mark all corrections at the appropriate place in the proof (e.g., by using on-screen annotation in the PDF file) or compile them in a separate list. Note: if you opt to annotate the file with software other than Adobe Reader then please also highlight the appropriate place in the PDF file. To ensure fast publication of your paper please return your corrections within 48 hours.

For correction or revision of any artwork, please consult http://www.elsevier.com/artworkinstructions.

Any queries or remarks that have arisen during the processing of your manuscript are listed below and highlighted by flags in the proof. Click on the 'Q' link to go to the location in the proof.

\begin{tabular}{|l|l|}
\hline $\begin{array}{c}\text { Location in } \\
\text { article }\end{array}$ & \multicolumn{1}{c}{$\begin{array}{c}\text { Query / Remark: click on the Q link to go } \\
\text { Please insert your reply or correction at the corresponding line in the proof }\end{array}$} \\
\hline Q2 & $\begin{array}{l}\text { Reference(s) given here were noted in the reference list but are missing from the text - please position } \\
\text { each reference in the text or delete it from the list. } \\
\text { Please confirm that given names and surnames have been identified correctly. } \\
\text { Uncited references: This section comprises reference that occurs in the reference list but not in the body } \\
\text { of the text. Please position each reference in the text or, alternatively, delete it. Any reference not dealt } \\
\text { with will be retained in this section. }\end{array}$ \\
$\begin{array}{l}\text { Please check this box or indicate your approval if } \\
\text { you have no corrections to make to the PDF file }\end{array}$ \\
\hline
\end{tabular}

Thank you for your assistance. 


\section{International Journal of Educational Development}

journal homepage: www.elsevier.com/locate/ijedudev

\section{Highlights}

\section{Identifying strategies to enhance the educational inclusion}

\section{of visually impaired children with albinism in Malawi}

Paul Lynch ${ }^{\mathrm{a}, *}$, Patricia Lund ${ }^{\mathrm{b}}$, Bonface Massah ${ }^{\mathrm{c}}$

${ }^{a}$ School of Education, University of Birmingham, UK

${ }^{\mathrm{b}}$ Faculty of Health and Life Sciences, Coventry University, UK

${ }^{\mathrm{c}}$ The Albino Association of Malawi (TAAM), Malawi

- Children with albinism experience different degrees of stigmatism in their communities.

- Few children are receiving adequate clinical eye and skin services.

- Resource centres are providing needed support to children with albinism, although few girls attend these centres.

- Itinerant teachers play an important role in protecting children with albinism in mainstream schools.

- There are gaps in teacher training courses that cover low vision which need addressing. 


\title{
Identifying strategies to enhance the educational inclusion of visually impaired children with albinism in Malawi
}

\author{
Q1 Paul Lynch ${ }_{\perp}^{\mathrm{a}, *}$, Patricia Lund $_{\perp}^{\mathrm{b}}$, Bonface Massah $_{\perp}{ }^{\mathrm{c}}$ \\ a School of Education, University of Birmingham, UK \\ ${ }^{\mathrm{b}}$ Faculty of Health and Life Sciences, Coventry University, UK \\ ${ }^{\mathrm{c}}$ The Albino Association of Malawi (TAAM), Malawi
}

\section{A R T I C L E I N F O}

\section{Article history:}

Received 15 September 2013

Received in revised form 4 June 2014

Accepted 1 July 2014

\section{Keywords:}

Albinism

Visual impairment

Resource centres

Teacher training

Special educational needs

\begin{abstract}
A B S T R A C T
Oculocutaneous albinism is an inherited condition with significant health and social impact on the lives of those affected throughout sub-Saharan, including in Malawi. Myths and superstitions surrounding the condition lead to stigmatisation, rejection and misconceptions. In a participatory study, consultations with educational professionals, children with albinism and their families documented the barriers to full educational access and revealed low-cost strategies that could be implemented in mainstream schools, to minimise the effect of the visual impairment associated with albinism. These were captured in two information booklets in English and vernacular, one for children and the other appropriate for teacher training.
\end{abstract}

(c) 2014 Elsevier Ltd. All rights reserved.

\section{Introduction}

I feared his hands; he had sores on them...my belief was that whenever you see an albino you have to spit saliva on your chest (Miles, 2011).

Children in African communities born with the genetically inherited condition oculocutaneous albinism are strikingly different from their peers. Instead of the usual dark pigmentation they lack melanin pigment in their hair, skin and eyes, making their hair sandy coloured, their eyes blue to hazel and their pale skin extremely sensitive to the damaging effects of the sun (Lund, 2005). The high risk of developing skin cancer makes it imperative that all those with albinism adopt sun protection strategies from birth, including wearing protective clothing and avoiding sun exposure as much as possible (Lund and Taylor, 2008). Less obvious are the eye problems associated with albinism: involuntary nystagmus causing their eyes to wobble involuntary from side to side, photophobia, poor depth perception, strabismus (squint), poor visual acuity, and refractive errors (Yahalom et al., 2012). An optometric study in South Africa found that $85 \%$ of the children

\footnotetext{
* Corresponding author.

E-mail address: p.lynch@bham.ac.uk (P. Lynch).
}

with albinism had less than 30\% vision, even with best optical correction (Raliavhegwa, 2001).

The very visible difference in appearance of those living with albinism can lead to a lack of acceptance and poor social integration. A myriad of myths and superstitions surround the condition (Baker et al., 2010; Braathen and Ingstad, 2006), leading to stigmatisation, rejection and a lack of understanding about albinism. Alex Munyere describing his personal experience of living with albinism in Kenya called it 'a disability that others do not understand' (Munyere, 2004). The vulnerability of people with albinism has been dramatically highlighted by reports of dismemberment and killings in Tanzania and other regions of central and east Africa, to obtain their body parts for use as 'good luck' charms (reviewed in Cruz-Inigo et al., 2011).

Albinism has been recorded throughout sub-Saharan Africa with estimated frequencies of between 1 in 2000-5000 (Hong et al., 2006); however there are few detailed epidemiological studies that provide evidence of the frequency of the condition in the region. Published data on the prevalence of albinism among schoolchildren in Zimbabwe and South Africa estimate that there are up to 7000 people living with albinism in Malawi, assuming a total population of 14.86 million and a prevalence of 1 in 2000 (Lund, 1996; Lund and Gaigher, 2002).

In order to help address the paucity of data on the lives of people with albinism, a small team of Malawian and UK researchers 
carried out a study to collect primary data about school children's experiences living with the condition in different educational settings in Malawi. Seeking to use participatory research techniques (Lynch et al., 2012), the team designed tools that could that could give equal opportunity and voice to children with albinism, their families as well as teaching professionals who supported these children in mainstream schools and resource centres. It was critical that this study could provide an insight into the educational and social events that impact strongly and negatively on the mental and social well-being of children with albinism.

\subsection{Different approaches to educating children and young people with albinism}

Children with low vision (including those with albinism) are often educated in specialist schools for the blind, outside the mainstream sector. A recent study carried out in special schools and resource centres in Kenya, Malawi, Tanzania and Uganda revealed that out of 1062 children assessed, 382 children had low vision (visual acuity $>$ or $=6 / 60$ ) and 120 had normal vision (Tumwesigye et al., 2009). Even though a high proportion of children could read print they remained in these educational establishments with blind children and did not have the opportunity to attend their local mainstream school.

Studies (Lund and Gaigher, 2002) at a special school for children with albinism in South Africa give an insight into their education in rural areas of the country. Although the school had access to magnifiers and other low vision devices, the pupils with low vision did not rely on these. They were used only for particular lessons such as map reading. The children with albinism at this school were all taught using print, none were taught Braille although this training was available for the totally blind. The school's aim was to teach the children skills that would enable them to integrate successfully into mainstream school at secondary level.

In nearby African countries, including Zimbabwe and Zambia, children with albinism attend mainstream schools, although inclusion in mainstream schooling can lead to challenges for both the children with albinism and their teachers. In an action research study in Zambia (Miles, 2011), one teacher of a boy with albinism expressed her fears of having 'an albino' in her class 'I was not so free with him, I feared his hands, he had sores on them...my belief was that whenever you see an albino you have to spit saliva on your chest'. Fear driven by superstitious beliefs has a negative impact on the way children are treated in education in sub-Saharan countries. Paucity of correct information about the condition at community level inevitably increases the probability of teachers drawing on local superstitions and myths (Baker et al., 2010).

\subsection{Disability in Malawi and primary education}

Disability issues are often marginalised or excluded from mainstream development strategies. People with disabilities encounter greater poverty than people without disabilities, across a variety of dimensions; including lower educational attainment, less access to employment and greater health related expenditure (Mitra et al., 2013). It is clear that today people with disabilities continue to be marginalised in both local and national development processes, and this marginalisation contributes to the high rates of chronic poverty among people with disabilities (MacLachlan et al., 2014). A recent project on African Policy on Disability and Development (A-PODD) identified negative societal and cultural attitudes as the major obstacle to inclusion, with a perception that people with disabilities are not 'useful citizens' and do not contribute towards the national development agenda (Mannan et al., 2012). Furthermore, there was a lack of empowerment on the part of those who are disabled to challenge and change this perception. The A-PODD study called for more disability-related research and information, including appropriate terminology, which has direct relevance to this study on albinism.

In Malawi, in spite of the signing and implementation of the Disability Act in 2012, there is a disconnect between departments and ministries whose mandates include the health, social welfare and education of people with disabilities (Sightsavers, 2012). The creation of a small Ministry of Disability and Elderly Affairs was considered to be a major breakthrough particularly in making 'disability' more visible in Malawi but the ministry has not been able to play a significant role in the delivery of a national development agenda. This is mainly due to the lack of funding and lack of specialist knowledge by ministerial personnel (Sightsavers, 2012). Significant gaps in knowledge about the main causes of disability and disease, particularly at the health sector level, coupled with inadequate sources of information that can be shared with families affected by disability have led 'people making up explanations, which could be connected to illness and disease' including those with albinism (Braathen and Kvam, 2008). People with albinism in Malawi are included under the umbrella body of the Federation of Disability Organisations of Malawi (FEDOMA), with their own national association, The Albino Association of Malawi (TAAM) established in 2005. TAAM has a good record in registering individuals with albinism, providing them with counselling on skin protection and fighting for their rights at all levels. The organisation raises community awareness about issues surrounding albinism through the media, talks and participating in research studies, including the one reported here.

The Malawian government, in line with neighbouring states, sets out goals of expanding equitable access, and improving quality, efficiency and governance of the educational process at all levels, from early childhood to tertiary education, in its Education Sector Plan (2008-2017). This plan recognises the challenges facing the system, particularly at primary level, due to increasing numbers of school enrolment of all children without adequate funding and management. Specific targets include improving distribution of teachers in rural areas from 1 qualified teacher to 90 pupils to at least 1:70. Special Needs Education programmes feature prominently in this plan, with a stated goal of moving towards a ratio of 1 teacher to 5 pupils in resource centres by 2017 , as well as introducing special needs education units in all teacher training colleges. Currently, resource centres which are attached to mainstream schools for children with visual impairment (13 in primary schools, 15 in secondary schools and 7 tertiary colleges) have up to 40 children with only two resource teachers supporting all the children in the centres (Lynch and McCall, 2007). Many resource centres and residing hostels were set up with the financial support of international non-government organisations (INGOs) to support the education of blind children in specialist curriculum areas such as Braille literacy, Braille maths and daily living skills (Lynch and McCall, 2007), but their intake has expanded to enrolling children with albinism.

A system of delivery was set up in the 1980s to help counter the 'segregationist' approach to educating children with visual impairment at resource centres, through the Malawi Integrated Education Programme (MIEP). This radical approach was set up by the Ministry of Education and Sightsavers, an INGO, to promote the 'integration' of children with visual impairment into mainstream local primary schools. In Malawi, cohorts of itinerant teachers (ITs), specially trained in visual impairment, have been deployed in selected districts across Malawi to conduct community awareness around visual impairment and support the transition of children with visual impairment and those with low vision to their local mainstream schools, rather than to a special school or resource centre extensive distances from their home (Lynch et al., 2011). For 
example, in 2010 the MIEP supported 90 children with low vision, of whom 66 (73\%) children have albinism, indicating that albinism is the major cause of low vision among the group on this programme in central and southern Malawi. Fifty-seven (63\%) of these children had received low vision devices (e.g. small telescopes or hand-held magnifiers) to use in the classroom but no follow-up evaluation of their use was undertaken and subsequent field visits found no evidence of these devices being used in classrooms. In one case a child reported using it at home but not at school; in another case the device had been 'lost'.

Although the title of 'IT' still exists, there is a noticeable move towards placing newly trained specialist teachers from Montfort Special Needs Education College into existing or new resource centres across Malawi. ITs have had a positive impact on the education of children with visual impairment in some education districts over the past 20 years, but this approach has been increasingly difficult to sustain partly because of lack of external funding and government 'buy-in' (Lynch and McCall, 2010).

International funding agencies (e.g. Japan Social Development Fund through the World Bank) have been working with the Ministry of Education and FEDOMA to develop pilot inclusive education in 150 primary schools in three districts. Additionally, UNICEF has also been supporting a human rights-based approach to Child Friendly School development (UNICEF, 2008). However, such initiatives have had limited impact on the quality of teaching in primary classrooms and has not led to systemic changes in educational policy towards inclusive education of children with disabilities (Grimes et al., 2013). In spite of these key donors' interest in supporting inclusive education, the Ministry of Education still continues to support the policy of educating children with disabilities in resource centres managed by specially trained resource teachers or special needs teachers (Lynch and McCall, 2010).

\section{Research focus and methods}

The study was designed within a participatory research framework with tools developed to encourage full engagement with participants (children with albinism, their families and teaching professionals) recognising the plurality of knowledge in different institutions, i.e. schools, teacher training colleges (Kindon et al., 2007). The field research was conducted over two visits to Malawi between 2010 and 2011. It gathered primary data in central and southern Malawi, from young school children with albinism, their families and educational professionals supporting these learners by investigating:

1. local explanations about the cause of albinism and traditional beliefs surrounding the condition;

2. the level of educational support offered by different educational professionals (itinerant teachers, class teachers) supporting children and young people with albinism;

3. the use of different learning media (print or Braille) by this group;

4. the health care issues associated with albinism and being at school;

5. the employment opportunities for those leaving school.

The study drew on a range of qualitative data gathering tools including:

- a questionnaire for itinerant teachers $(n=16)$ from two neighbouring districts (one urban and rural) in the centre of Malawi:

- focus group discussions with the same ITs;
- focus group discussions with 30 parents of children with albinism who attend resource centres:

- semi-structured interviews collecting data from class teachers in mainstream schools and resource teachers $(n=16)$,

- semi-structured interviews with a total of 60 children with albinism (40 boys and 20 girls) at resource centres and mainstream schools.

Although albinism affects both genders equally, the number of girls attending resource centres is significantly lower than boys. (Current records from the Ministry of Education estimate there are 48 boys and 22 girls). The significantly lower number of girls being educated was a cause of concern for the research team. Explanations for gender disparity could be the result of parents concerns about the protection of girls in residential settings, which are mainly managed by male members of staff.

Observations of individuals with albinism on visits to resource centres gave the researchers the opportunity to assess the children's 'functional vision' without the children using any additional low vision devices. The 'draw and write' technique (Bradding and Horstman, 1999) which has been used in a variety of disciplines such as health education was adopted as a discussion starter and a method to help empower the recruited children to express their views (Lambert et al., 2013). This method is considered more useful for younger aged children (6-8 years) giving them something concrete and active to focus on, rather than talking directly to a stranger (Punch, 2002). Children were given different drawing and colouring materials and asked to produce line drawings and collages of places that were of particular significance to them, or to tell a story about what they enjoy doing at school or at home. The final pieces of work provided the interviewer from TAAM with a good stimulus for interactive dialogue about their lives at school and at home. All the children, both younger and older, produced a variety of drawings and pictures, with some containing text.

Ethical approval for the study was obtained from the University of Birmingham Research Ethics Committee and from the Special Needs Education Directorate at the Ministry of Education in Malawi. Invitation letters briefed all participants (parents, teachers and children) about the project and what was expected from them before asking for their signed consent to participate in the study and for their image and words to be used in the development of information booklets on albinism.

The MIEP database held by Sightsavers and that of The Albino Association Malawi were used to recruit participants at two resource centres (one near Lake Malawi and a second near Blantyre City) and a school for the blind. Additional interviews were carried out with families in Mchinji District. Two-thirds of the children interviewed resided at one of the three resource centres visited over the two-year period.

A field report of the study was shared with stakeholders consulted in the study, including the study commissioner, before publishing and disseminating more widely (Lynch and Lund, 2011). This provided the evidence base to develop two information booklets, one for teachers, giving them practical information on how to support children and young people with albinism in school and another aimed at children and young people with albinism. Both booklets have been widely distributed across Malawi.

\section{Findings of the study}

The evidence indicates that both children with albinism and their families experience a range of cultural and social events that impact strongly and negatively on their mental and social well-being. 


\subsection{Children's experiences of their condition and how they are treated}

Children with albinism were asked about how the 'condition' of albinism affects their daily lives, particularly in relation to how they are treated at school and in their community. Nearly half of the children interviewed $(n=27)$ said that they had heard stories and myths about albinism which caused them anxiety or made them feel vulnerable. Almost all the children we interviewed at the resource centres and those attending mainstream schools $(n=55)$ said that they had experienced name calling and bullying at some time in their lives. In spite of their fears and concerns about societal attitudes, about half of the children who attend the resource centres said that they enjoyed going home to see their families during the school holidays. One 18 year old man in Grade 7 (upper primary) said that he liked to tend to his parents' garden growing maize, tobacco and ground nuts when he went home. He felt sad when he had to return to the hostel as he missed his parents. A young girl attending a primary school in Dedza said she heard people in her community say that 'albinos do not die but just disappear...so you can't see where their bodies are as with other people [non-albino].' Another girl in the same district heard that albinism 'is a disease that affects the woman when pregnant. . others say albinos do not die a normal death.' One young man in Lilongwe Rural said that he had heard that they [people with albinism] can be killed and used as magic to get rich. This results from families hearing about 'muti' killings ${ }^{1}$ in Tanzania, as well as widely broadcast news reports by international media agencies.

Over three-quarters of the children interviewed at the resource centres and three children in mainstream schools said they were curious about the causes of albinism and wanted to know what they can do to protect themselves against the dangers of the sun. In many respects, they were strong advocates for themselves and were able to voice their needs and concerns. Again, it was the older children who were more able to discuss the issues that had been affecting them for many years. Some had received answers from doctors and other medical staff at hospitals they attended, their families or from visiting itinerant teachers. About a third of the children $(n=10)$ residing at the resource centres had become more knowledgeable about the biological cause of albinism and how they should protect themselves, mainly because the resource teachers provided the children with information verbally. The same teachers said they lacked any written information to show the children but they said they had covered aspects of albinism as part of their specialist teacher training at the principal teacher training college that specialises in special educational needs. When asked if they would like to learn more about their condition, about $80 \%(n=49)$ of all children interviewed in the resource centres and mainstream schools said they would like to know more about why they became 'white and not black' and learn about ways to cope with any difficulties they may be face at different stages of their childhood and early adult lives.

\subsection{Assessment of visual acuity and functional vision}

This study provided evidence that very few learners have had a clinical assessment of their vision at a hospital or clinic apart from a small number supported by the ITs in Blantyre Urban and Rural districts. When asked about screening of children with albinism, ITs consulted their caseloads and identified only 13 children who

\footnotetext{
Muti is a term for traditional medicine in Southern Africa as far north as Lake Tanganyika. The word muti is derived from the Zulu word for tree. More recently muti victims have been children in Eastern Africa where their body parts have been traded locally also often transported across borders of various countries where there is demand.
}

had received clinical assessments out of a total of 30 children in one rural district; however the number was significantly higher (34 out of 45 children) in a neighbouring urban district attending mainstream schools. None of the children we interviewed in the three resource centres we visited had received a clinical assessment. Around half of the ITs $(n=7)$ said they carried out functional assessments of identified children with low vision ${ }^{2}$; including those with albinism but they did not follow any specific standard assessment procedures or use a recommended lowvision kit and instruction manual (e.g. The Centre for Eye Research Australia-low vision kit).

Observations carried out at the resource centres provided some very useful data about how all the children used their vision in the classroom. Although the planned intervention was short and could only provide some evidence, it was clear that all the children were adept at using their vision extremely well by turning their head slightly to a position, i.e. the 'null' point, to afford better gaze or focus or bending down very closely to the desk or table to visually locate and discriminate the different coloured materials presented to them. All the children produced visually rich and detailed pictures or collages; some with writing, others produced labelled drawings. The older children were able to produce very detailed coloured-in line drawings of 'everyday objects or buildings that were important to them' (e.g. their homes, granary, bicycles, minibuses) or of activities they did on a regular basis, such as carrying water from the well, playing football with friends, or walking to school. The younger children were more interested in doing art activities, using glue and different coloured paper and feathers, with some help from an adult.

If there are more activities, they can learn more. I saw one draw a lovely tree [during an earlier drawing activity with a group of learners]... if they have coloured materials, they can enjoy it. We only have access to textbooks...almost all the children [with albinism] are learning Braille. May be we could bring them back to using print, may be they could manage (a teacher at a resource centre).

\subsection{Uptake of low vision devices}

Only three children who attend a resource centre said they had received prescribed spectacles and in some cases a magnifying glass. The ITs, during a focus group discussion, raised concerns about the little actual hands-on training they had received on low vision devices (LVDs) or how to apply low-cost solutions and techniques to enhance children's access to printed text. Data from the questionnaire confirmed that none of the ITs had received any training on how to use LVDs or had information about the most basic types of LVD such as a reading stand for children. In spite of this lacuna in skilled knowledge, ITs were still expected to provide timely advice to class teachers on how to use these devices and show children how to use them correctly. There was also a lack of monitoring and evaluation of any prescribed LVDs in terms of acceptance or usability by the children themselves. This could partly be due to the fact that many of the devices are prescribed by eye clinical services to the children and their families without any consultation with the ITs, who in turn do not encourage the children to use them in class.

Given the low up-take of LVDs, a hand-held bright magnifier was given to one older boy aged 14 , as a trial. He was shown how to

\footnotetext{
${ }^{2}$ This is an assessment to determine how an existing or potential visual impairment may affect a student's performance, for example, at school. Qualified teachers of visually impaired students assess such visual functions as near and distance acuity, visual field, colour perception and contrast sensitivity (RomanLantzy, 2008).
} 
use the magnifier and asked to try it out at school for three months. Although the magnifier could be kept in a pocket and used discreetly, he did not use it at school as he said that other pupils 'disturbed him as they also wanted to use it for fun'. He, however, used it for his homework.

\subsection{Stories and myths about losing vision}

It was interesting to witness how the different children were able to use their residual vision effectively to draw and write even though the teachers and lecturers interviewed strongly supported the teaching of Braille. There is a general belief that people with albinism will develop severe sight loss as they become older which could lead to blindness. This misconception originates from teacher training professionals and filters through to school teaching staff including head teachers, resource teachers and district education management. One lecturer interviewed said, 'most have low vision... when they are aging they might end up with blindness, they can learn Braille instead of large print'. Part of this belief is promulgated by eye clinicians who do not provide accurate information about children's vision in the long term. The teachers in mainstream schools also believed that as children with albinism become older, their vision also deteriorates. This belief can be confirmed when the children themselves say they are experiencing problems reading small print or reading off the chalk board. About a third of the children interviewed said that they had difficulties reading print but this was because they said they did not have access to their own reading book and had to look over the shoulder of a fellow pupil to see the book.

\subsection{Family perspectives on albinism}

Families of the children interviewed at the three resource centres $(n=30)$ were asked about their own beliefs surrounding the condition of albinism. A commonly held belief was 'God has wanted it to be' or as one mother remarked, 'having some infection in the womb which made the baby white (mwanaphepo)'. This issue of 'infection' or 'disease' was raised by families on several occasions during the focus group discussions. There was even a fear that the condition could be passed from a person with albinism to a normally pigmented person if a 'non-albino' pregnant woman comes into close contact or looks at a person with albinism.

In my village when a woman is pregnant they say that my child [with albinism] should not come close to her or the woman should not look at her or carry her, because she will give birth to an albino. This I have experienced so. ...and it is very common in our village, especially to elderly women when talking or giving advice to pregnant women, (mother of a young boy with albinism).

Conversely, eight families interviewed at the resource centres showed a strong sense of self-efficacy, spirituality, agency and resilience when narrating their personal experiences. For example, some families considered the birth of a child with albinism as 'a gift from God' or 'the will of God' in a positive sense. They were able to hold this view in spite of the significant negative and sometimes violent reaction they received from their own family, particularly immediate members such as their husband or partner, but also from their community.

Since the child was born other women could laugh at me asking me how could I choose to give birth to an albino child. . .but I tell them that it's God's plan and I need to receive it like that, because I also don't know why God gave me a child like this one. My husband used to ask me why I gave birth to an albino. I told him that it's a gift from God, (mother at focus group discussion).
As for me, if there is the chance for someone to tell me about albinism I will be happy. . I may want to know, but I think it is not very necessary. I don't see any problem, because I know any woman can give to a child with albinism based on the will of God, (mother at focus group discussion).

Disturbingly, one mother interviewed explained how her husband wanted her to kill her first born child who had albinism. During an individual interview, a mother of a 14 year old son with albinism, testified how her husband had become depressed after the birth of their boy and decided to leave her and two older children with black (normal) pigmentation to 'take another wife' in another part of Malawi. In spite of these incredible challenges, the mother raised her son with love and compassion and ensured he went to his local school.

\subsection{Information about albinism for children with albinism}

Parents of the interviewed children felt they could go to their local organisations, particularly FEDOMA and TAAM to find information, or visit a skin clinic or talk to other families who have children with albinism in the hope of reducing isolation in their own community and enable them to cope with the external pressures that they and their children face. Many families were able to recall instances when they had met or seen people with albinism in their immediate or extended family. Families who had access to the right clinical services, schooling (e.g. resource centres) and advice (TAAM) felt better placed to make decisions about their children's physical and emotional well-being and education.

We are taught on how to use the lotion but in some cases we just read from the instructions on the bottle. As for my child when I bathe him I wait for him to dry then I apply the lotion and keep him in the house. I apply in exposed areas like the face, around the ears and neck and sometimes the legs. When 30 minutes are over I let him go out and play, (mother of a child who attends a primary school).

I was lucky to have met a person who introduced me to the resource centre. Before he came my son used to have sun burn and blisters on his lips because we didn't have the means to support him, (father of a child attending a resource centre).

\subsection{Sun protection strategies}

The protection of skin was also a major area of interest in this study, particularly in a sub-Saharan African context where children are exposed to sunlight all year round. During the interviews the researchers could see the results of varying degrees of individual sun exposure and the extensive damaging effects that sustained periods of time out in the sun had on the children's exposed skin. Some children had scaly tough skin on their necks (solar elastosis) with red, burnt skin which attracted unwanted attention from other people in their community. Only a very few children we interviewed were blemish free.

Sometimes other children call me red man or white man but without worth [money], (11 year old boy attending a resource centre).

Those who had hats wore them to the interview but in many cases they were either too small, worn out, torn or a baseball design that provided inadequate protection to the face and neck. The hats distributed to children were often donations from benefactors or from NGOs visiting resource centres or were donated to TAAM to distribute to individuals with albinism. In addition, many had blisters on their lips which often remain and become re-infected and sore. 
The ITs were aware of the danger of the sun and how it could cause irreparable skin damage to children and young people with albinism. In response, they felt it was their duty to go to the skin clinic at a main hospital in Blantyre to collect skin lotion for the children on their caseload and show them where and how to apply it. They were also well informed by attending meetings at open days organised by the FEDOMA and TAAM. Children living in the urban district we visited were more likely to receive a sun lotion to help protect them from the sun.

\subsection{Supporting children at resource centres attached to mainstream schools}

Families with children attending the three resource centres talked openly about the difficulties they faced in deciding whether to send their children to school because of the negative advice they receive from others in their own communities. In some cases, parents were told that it was not worth educating them. Another reason for not sending their children to school was because they were worried about the amount of protection teachers would give them in school and whether their children would feel safe and 'happy'. Those parents who had sent their children to mainstream schools were generally dissatisfied with the level of care and protection that their children had received from class teachers. This resulted in them taking their children out of local schools and sending them to a residential resource centre where they thought they would receive better protection and ultimately a better quality education.

I recommend and prefer the resource centres because there is no stigma and the teachers understand the albino child better. They don't say that we will only favour those who we look alike [with normal black pigmentation]. There is also so much love given to the pupils by the teachers because there are many children who are albinos at one school, (father of a child who attends a resource centre).

The implications of sending their children to these centres were huge in terms of the teaching approaches used (i.e. Braille as the principal teaching medium) as well as the impact of living away from their families on their social and emotional well-being, but some parents felt they needed to send their children to resource centres. In a small number of cases, parents said they wanted to send their children to the local primary school in spite of the large class sizes and poor limited knowledge that class teachers had about supporting children with albinism.

Parents of children who had attended mainstream schools and then been sent to resource centres had strong views about how mainstream schools could improve the learning experiences of all children with albinism. They felt that teachers played an important role in caring for the children, helping them to choose a friend in the classroom who can aid them with their school work; preferably someone who had clear handwriting, as well as a buddy who could make sure they were not excluded during recreation times. They also felt that teachers could give them duties indoors so they were not outside at the hottest time of the day, and organise games in a shaded part of the school grounds so that children with albinism could participate fully. They should also know that children with albinism need to wear protective clothing, even if it is not the regulation school uniform.

When interviewed, four teachers at one of the three resource centres expressed strong concerns about the placement of children with albinism in mainstream school, saying that resource centres are the most appropriate form of school to educate these children. They were aware of the challenges that children with albinism face in their own communities on a daily basis and considered resource centres to be safer places for them to live, not constantly to have to face the pressures of 'looking different'.

\subsection{Employment opportunities}

Two close relatives of children with albinism questioned the purpose of schooling for these children especially when employment prospects are poor for this group. An uncle of a young man with albinism could not see the value of school if 'these children could not find work'. He placed part of the blame on the government in not helping young people to find suitable work.

I can challenge you that I have not seen any albino with a good job whether in government or private sector. So as parents we may have the will to support them to go to school but we see other albinos who have gone to school but cannot get a job. My plea would be to the government to consider albinos for employment, (uncle of boy with albinism at focus group discussion).

In spite of the poor employment prospects for people with albinism, some enter the teaching profession. An interview with a recently qualified female primary school teacher showed how she had managed to ensure a good school education herself. This teacher showed great determination in seeking appropriate support at school, asking her class teachers to lend her books so that she could do her own private reading. At home, she was equally resourceful in asking her siblings to help her copy the teachers' notes.

I started Standard 1 and then I was not realising that I have low vision. I realised when I was in Standard 4...in the first three years I thought that everyone has the same vision as I have. I was unable to see on the chalkboard and then, after I realised that I have low vision, then I started following the teacher, saying 'can you borrow me some books?' I told him that I have a problem to see on the chalkboard and then he was giving me the book.

A male primary school teacher with albinism, who taught for over 15 years in rural Blantyre said that he had experienced some problems with his employer in the past, particularly in relation to travelling long distances (up to $8 \mathrm{~km}$ ) to school and being exposed to the sun. He was transferred to a school house which is situated $100 \mathrm{~m}$ from the school. He had not experienced any difficulties with fellow members of staff or children in his class, but had difficulties when outside teaching sports activities to all the classes. He said 'it affects my skin during the hot season and I find it difficult to see and my eyes become watery...I don't have sunglasses.' Both teachers' testimonies indicate that they were treated with respect and due consideration at the schools where they worked.

\subsection{Role of itinerant teachers (ITs) and strategies to support children in mainstream school}

Evidence from focus group discussions indicate that ITs play an important role in supporting children with low vision who go to mainstream schools. The majority of children with low vision have albinism. For example, six ITs said they supported between five and six children with albinism and one said she had eight children on her caseload. The frequency of visits varied from once a week to once every month. The amount of time they spent with children varied considerably between visits-from an hour to almost a whole school day (approximately $5 \mathrm{~h}$ ). The travel distance from their base schools to the child's school was an important factor in deciding how much time they could realistically spend with each 
child at school. Nearly all the ITs had to rely on public transport or use personal bicycles, with some journeys taking up to half the day.

ITs felt positive about the inclusion of children with albinism in mainstream schools and believed many of the strategies they were utilising were having a positive impact on the children. They strongly believed in increasing access to the curriculum (by providing large-print versions of text books) as well as encouraging them to move close to the chalkboard when copying and participating in all activities inside and outside of the classroom. They also considered their role to be one of supporting and advising the class teacher. Class teachers may not always be aware that all children with albinism have varying degrees of low vision and will take longer than their normally sighted peers to read information. Strategies suggested by ITs to support children with albinism included allowing them extra time to complete reading and copying tasks and pre-preparing large print copies of examination scripts and allocating additional time to complete school and state examinations. Teachers were also advised to encourage these children to wear clothing to protect their skin from the sun and to allow them to wear their hats in the classroom to protect their eyes.

Class teachers revealed that they could be more supportive of children with albinism as long as they were able to draw on support from an IT. All primary school teachers had received some training in special needs education as part of their pre-service training course but did not feel equipped to teach children with visual impairment (including children with low vision). Teachers who had received advice from ITs on how to support children with low vision in their class felt more confident in teaching individual children. For example, they encouraged those with albinism to move close to the chalkboard, if necessary. Children interviewed in the same schools confirmed that they were free to sit near the chalkboard. All teachers interviewed said they tried to write bold, clear letters on the chalkboard and in two schools, class teachers were producing worksheets in large print. One boy attending a mainstream school reported:

When I am at school, I sit in the sideways [window side], but I like to sit in the middle but sometimes the seats are filled by other pupils.

The ITs, who had completed the one year certificate in Special Needs Education specialising in how to teach children with visual impairment (now replaced with a two-year diploma) at Montfort Special Needs Education College, had a clear idea about the challenges that people with albinism faced. Lecturers who run the training college for SEN in Malawi said they covered some aspects about albinism, for example, how to help these children in the classroom but it tended to be dispersed across other module areas (e.g. low vision). The new syllabus, launched in 2010, still contains very little on the condition of albinism or on how teachers can help to support children with albinism at school. The lecturers also shared some of the challenges they faced in getting up-to-date information about albinism which they could integrate into their lecturing materials and requested help with filling the gaps in knowledge. A number of these areas are being addressed in a related study led by Coventry University, which builds on the findings from this research.

\section{Discussion}

This study focussed on identifying and documenting the activities and educational participation of pupils with albinism in Malawi and on identifying effective strategies for alleviating any limitations, rather than adopting a medical (impairment based) model. Observing the ability of this group of children with low vision to produce detailed drawings in their usual school environment demonstrated their capabilities to maximise their vision, rather than concentrating on their limitations. This study therefore focussed on identifying ways to education through accommodation of children with albinism without relying on expensive low vision devices, given the evidence that they are hardly used, even if they are available.

The involvement of the local association TAAM from the inception of this project was crucial to its success. The director of TAAM was a member of the research team and took part in field visits, thus alleviating any trepidation participants may have felt when visited by UK based researchers. Sensitive questions were asked about their lives, and participants felt comfortable being interviewed (in their own language) by a member of TAAM and knowing that the study was being used to influence government policy and in advocacy, promoting awareness and providing information about albinism. It was important for TAAM and Sightsavers to learn first-hand about the social and cultural challenges children with albinism and their families faced when making important decisions about education and their future.

Although this study documents variations in the experiences, in the modes of education and in the degree of visual impairment of children with albinism, some general guidelines can be applied. Simple, low-cost accommodations to the every-day environment and teaching methods, which can be applied on the first day a child with albinism starts school, as well as appropriate support by specialist ITs, were suggested by families of children with albinism. These suggestions are developed further in the following sections.

\subsection{Parental responses to the social complexities of albinism}

This study revealed that children with albinism and their families experienced a range of negative views and perspectives from their communities. These, in turn, impacted strongly on their mental and social well-being as well as their parenting. Despite limited resources, parents and older children interviewed showed great resiliency and agency in being able to deal with these barriers in different and courageous ways.

Children and their families expressed an interest in finding out more about the condition of albinism in terms of its genetic origins and learning how to protect their eyes and skin more effectively. The national association supporting families with albinism, TAAM, plays a key role in organising workshops and training that include children and adults with albinism, recognising their knowledge of the condition. It is important that families living in rural areas are able to benefit from the association's work particularly in relation to where they can receive help from local services and counselling from members of the association. TAAM has started to develop a data base of families with albinism; to share experiences nationally and regionally and to provide a point of contact for children and their parents to learn from each other and relieve isolation.

There was a consensus among parents interviewed that those with experience and knowledge about albinism should take an advocacy role, for example, visiting villages to talk to the village elders and their communities about albinism and to try and dispel any negative or harmful myths that could prejudice people with albinism. Families were able to draw on their own spirituality (or religious beliefs) to find explanations that could help them to explain why their child was different. These 'explanations' also gave them the resilience to face adversity from their own family and their community (Muthukrishna and Ebrahim, 2014). Not only did they have to face the trauma of having a baby with albinism, but also had to cope with accusations of being the 'wrong-doer' with eventual abandonment from their husband or partner, who could become invisible in the care of the child with albinism (Grut and Ingstad, 2005). 
In African populations albinism is a very visible but often misunderstood condition (Lynch and Lund, 2011). At present it is unlikely that those with albinism will receive regular optometric services or specialist eye care until more eye specialists are trained and deployed to eye clinics in Malawi. As a consequence, there is either a failure to recognise the visual impairment always associated with albinism, or a misconception that this will lead to complete blindness. The general view that children with albinism develop blindness is widespread across the medical and educational sectors of Malawi and is resulting in children being taught Braille when they do not require it. In some countries those with albinism are legally 'registered blind', although this does not mean they have no vision. This may have resulted in this erroneous belief. The teaching of Braille to children with albinism is being phased out in Malawi, but is still being conducted in neighbouring countries such as Zambia.

Evidence from the study suggests that LVDs are scarce in supply, limited in the range of choices for children and even when distributed, are not being used by the beneficiaries. This study did not find any locally manufactured LVDs and imported devices are expensive and out of the reach of most families, unless provided by NGOs. Although this study has shown that children with albinism are successful without any access to a LVD, such devices (such as a simple, hand held and low cost magnifiers) have potential to enhance their educational experience, making tasks such as reading maps and drawing graphs easier. Any introduction should be negotiated with the child to find out if and how they would wish to use the device. There was little evidence of children being consulted about the type of hat (or umbrella) that would best suit their personal needs. This medical 'expert knows best' top down approach does not respect their views and desires. Using a very obvious device such as a telescope in a crowded classroom could make the child a target for mockery. The class teacher has a key role in explaining to the rest of the class why a child needs to use a particular device, or wear a hat in class. All the children interviewed in this study, who had been prescribed LVDs, said they were not asked about what would be the best solution for them. A more bottom-up approach which respects children's views and desires could actually result in more children not choosing to use LVDs but more culturally sensitive and less costly resources such as hats.

\subsection{Deciding on most appropriate educational provision}

The study identified different models of educating children with albinism-either in mainstream schools or in boarding establishments at mainstream schools with a resource centre attached. Although, the resource centres were originally established to educate blind children in the late 1960s, children with albinism now take up to a quarter of all residential places. The Malawian Government, through the 'Implementation Guidelines for the National Policy on Special Needs Education (MoEST, 2009), has been promoting the mainstreaming of children with low vision in Malawi at primary and secondary schools with specialist teachers (ITs) to visit them on a regular basis, although numbers of these teachers are very low in some of the education districts (e.g. only two ITs to cover the whole of Chikwawa district) and many are unable to travel to schools because of lack of personal transport. Despite these efforts the reality is that many children with special educational needs join crowded classes in mainstream schools without any additional support. This study provides evidence to support appropriate allocation of teacher resources for pupils with albinism in mainstream schools, including class teachers and special needs teachers. It also acknowledges the important role that resource centres have played and continue you play in protecting these vulnerable children and giving them an opportunity to receive some specialist tuition to help them with their studies. The biggest challenge for the children attending the resource centres has been the misguided policy of teaching them Braille beside their blind peers when they should be given useful LVDs and printed text in large print. If there is a continued movement by the Government to educate children with albinism in resource centres, then more has to be done to ensure teachers understand the specific needs of this group.

To help respond to stakeholders' questions and misconceptions about the condition of albinism, the research team developed two booklets (one for children with albinism and one for teachers) in collaboration with TAAM. It was important to give a positive focus, stressing what children with albinism can do, and seeking their input rather than adopting a 'top-down' approach with information written only by professionals. The children's booklet has been translated into Chichewa as Chewa is the largest ethnic group in Malawi. Feedback was obtained on the initial drafts from a wide range of stakeholders and used to refine and develop the information provided. The importance of ownership and validation of the booklets by the government through the Ministry of Education was a key element of this feedback. Without this official approval it would be very difficult to distribute the booklets to teachers in schools.

\subsection{Teacher training issues}

This study identified gaps in teacher training programmes, both at initial teaching level and at a specialist level, with teachers struggling to know what to do when they have children with albinism in their class. Lecturers did not have access to relevant, up-to-date information about how to provide teachers with low cost solutions to make children's experiences at school more enjoyable and rewarding. The research team responded to this gap in knowledge and understanding by producing an easy-to-read information booklet for teachers.

Miles (2011) believes that reflective writing and in-service training workshops are likely to be far more effective in challenging negative attitudes and superstitious beliefs than delivery following a curriculum at a teacher training college which simply informs teachers that they should have positive attitudes towards children with a range of learning difficulties and impairments. Opportunities to engage with people with disabilities and their advocates during initial teacher training can provide a way for addressing negative attitudes towards people with disabilities and for encouraging more positive position towards inclusion (Forlin, 2010). There is a strong case for forging greater links between teacher training institutions and schools as well as 'greater cross-pollination between special education and other disciplines during initial training' (Avramidis and Norwich, 2002) in order to meet the needs of teachers in heterogeneous classrooms. To respond to this need, this project involved developing case studies on albinism for use in training, so that the issues can be viewed in a real life context. In an extension of this project, targeted training workshops have been implemented at teacher training colleges to train the lecturers and develop an action plan for integration of albinism into various aspects of the existing curriculum, not only into topics relating specifically to low vision, but also into other areas such as social studies, early childhood development and education by discussing societal attitudes towards albinism. A more specialist workshop has been introduced at the principal SEN training college in MalawiMontfort Special Needs Education College-as well as a revision of current specialist curricula to include more aspects on albinism. 


\section{Conclusion}

This study has been able to identify and discuss some of the main issues around the education of children with albinism in Malawi through the lives of families who are marginalised by the condition. This research afforded the opportunity to explore these issues with the different stakeholders and to identify solutions that would lead to improved quality of life for children with albinism living in hostels which are attached to the resource centres and in traditional rural communities. There was strong evidence that the children and their families faced multiple prejudices and experienced insecurity in their communities and at school which led to feelings of anxiety and disablism, and more noticeably detachment from the communities. There is a paramount need for recognition and intervention to assist these children from birth and throughout their school careers. Sometimes, the final choice is based on important factors such as poverty, fears of safety for their children, or a persuasion that one type of education is better suited to their children's visual impairment or skin condition. These factors have a strong impact on the quality of education their children receive and whether they will be able to enjoy an improved quality of life and be able to take more control of their destiny through meaningful employment and a more equal place in Malawian society. Key agencies (including the Malawian Government) responsible for the education, health and well-being of children with albinism need to work together to support families to make important decisions about their education and future employment prospects.

\section{Q2 Uncited reference}

$$
\operatorname{MoEST}_{\perp}(2008) \text {. }
$$

\section{Acknowledgements}

The authors of this paper would like to express their heartfelt gratitude to all the participants in the study for their openness in sharing experiences and their enthusiastic involvement in the project. They gratefully acknowledge funding from the Commonwealth Secretariat and the British Academy as well as funding and logistical assistance from Sightsavers Malawi Country Office. Thanks are also extended to the Ministry of Education, Science and Technology for supporting the research and permitting the researchers to visit schools and interview the children and staff. Very special thanks to Professors Julie Allan and Ann Lewis for their valuable comments on earlier versions of this paper.

Copies of the booklets developed during the research can be accessed at http://wwwm.coventry.ac.uk/researchnet/cucv/Pages/ Profile.aspx? profileID $=589$.

\section{References}

Avramidis, E., Norwich, B., 2002. 'Teachers' attitudes towards integration/inclusion: a review of the literature. Eur. J. Spec. Needs Educ. 17 (2), 129-147.

Baker, C., Lund, P., Nyathi, R., Taylor, J., 2010. The myths surrounding people with albinism in South Africa and Zimbabwe. J. Afr. Cult. Stud. 22 (2), 169-181.

Braathen, S.H., Kvam, M.H., 2008. 'Can anything good come out of this mouth?' Female experiences of disability in Malawi. Disabil. Soc. 23 (5), 461-474.

Braathen, S.H., Ingstad, B., 2006. Albinism in Malawi: knowledge and beliefs from an African setting. Disab. Soc. 21 (6), 599-611.

Bradding, A., Horstman, M.G., 1999. Using the write and draw technique with children. J. Oncol. Nurs. 3 (3), 170-175.

Cruz-Inigo, A.E., Ladizinski, B., Sethi, A., 2011. Albinism in Africa: stigma, slaughter and awareness campaigns. Dermatol. Clin. 29 (1), 79-87.

Forlin, C., 2010. Reframing teacher education for inclusion. In: Teacher Education for Inclusion: Changing Paradigms and Innovative Approaches. Routledge, London.
Grimes, P., Engelbrecht, P., Waliuya, Dixon, F., Nthambi, T., 2013. Promoting Inclusion of Children with Disabilities into Basic Education in Malawi: Situation Analysis. Federation of Disability Organisations Malawi, Lilongwe.

Grut, L., Ingstad, B., 2005. Using Qualitative Methods in Studying the Link between Disability and Poverty: Developing a Methodology and Pilot Testing in Kenya. The World Bank, Washington.

Hong, E., Zeeb, H., Repacholi, M., 2006. Albinism in Africa as a public health issue. BMC Public Health, http://dx.doi.org/10.1186/1471-2458-6-212.

Kindon, S., Pain, R., Kesby, M., 2007. Participatory Action Research Approaches and Methods: Connecting People, Participation and Place. Routledge, London.

Lambert, V., Glacken, M., McCarron, M., 2013. Using a range of methods to access children's voices. J. Res. Nurs. 18 (7), 601-616.

Lund, P.M., 1996. Distribution of oculocutaneous albinism in Zimbabwe. J. Med. Genet. 33 (8), 641-644.

Lund, P.M., Gaigher, R., 2002. A health intervention programme for children with albinism at a special school in South Africa. Health Educ. Res. 17 (3), 365-372.

Lund, P.M., 2005. Oculocutaneous albinism in Southern Africa: population structure, health and genetic care. Ann. Hum. Biol. 32 (2), 168-173.

Lund, P.M., Taylor, J., 2008. Lack of adequate sun protection for children with oculocutaneous albinism in South Africa. BMC Public Health, http://dx.doi.org/ 10.1186/1471-2458-8-225.

Lynch, P., McCall, S., 2007. Unpublished report of scoping visits to Kenya and Malawi as part of a study to investigate how children learn to read and write BrailleIn: Commissioned Report for Sightsavers.

Lynch, P., McCall, S., 2010. Impact of educational inclusion on children with visual impairment in Malawi. The Educator 23 (2), 45-50.

Lynch, P., McCall, S., Douglas, G., McLinden, M., Mogesa, B., Mwaura, M., Muga, J., Njoroge, M., 2011. Inclusive educational practices in Kenya: evidencing practice of itinerant teachers who work with children with visual impairment in local mainstream schools. Int. J. Educ. Dev. 31 (5), 478-488.

Lynch, P., McLinden, M., Douglas, G., McCall, S., 2012. Developing participatory approaches for use in an action research project with teachers who support children with visual impairment in Kenya and Uganda: reflections on the relational praxis between participants and research institutions. Res. Compar. Int. Educ. 7 (3), 282-295.

Lynch, P., Lund, P.M., 2011. Education of children and young people with albinism in Malawi. In: Final Report. Commonwealth Secretariat, London.

MacLachlan, M., Mjib, G., Chataikac, T., Wazakili, M., Dubee, K., Mulumbaf, M., Massah, B., Wakeneh, D., Kalloni, K., Maughanj, M., 2014. Facilitating disability inclusion in poverty reduction processes: group consensus perspectives from disability stakeholders in Uganda, Malawi, Ethiopia, and Sierra Leone. Disabil. Global South 1 (1), 107-127 (2014 open access).

Mannan, H., McVeigh, J., Amin, M., Macachlan, M., Swartz, L., Munthali, A., Van Rooy, G., 2012. Core concepts of human rights and inclusion of vulnerable groups in the disability and rehabilitation policies of Malawi, Namibia, Sudan, and South Africa. J. Disab. Policy Stud. 23 (September (2)), 67-68.

Miles, S., 2011. Exploring understandings of inclusion in schools in Zambia and Tanzania using reflective writing and photography. Int. J. Inclus. Educ. 15 (10), 1073-1102.

Ministry of Education, Science and Technology, 2008. National Education Sector Plan 2008-2017 Malawi.

Ministry of Education, Science and Technology, 2009. Implementation Guidelines for National Policy on Special Needs Education Malawi.

Mitra, S., Posarac, A., Vock, B., 2013. Disability and poverty in developing countries: a multidimensional study. World Dev. 41 (C), 1-8.

Munyere, A., 2004. Living with a disability that others do not understand. Brit. J. Spec. Educ. 31 (1), 31-32.

Muthukrishna, N., Ebrahim, H., 2014. Motherhood and the disabled child in contexts of early education and care. Childhood, http://dx.doi.org/10.1177/0907568214 524233.

Punch, S., 2002. Research with children: the same or different from research with adults? Childhood 9 (3), 321-341.

Raliavhegwa, M., 2001. Vision problems among children with oculocutaneous albinism attending special education schools in the Northern Province of South Africa. In: Unpublished Master's Thesis. Department of Optometry, Faculty of Health Sciences, University of the North, South Africa.

Roman-Lantzy, C., 2008. Cortical Visual Impairment: An Approach to Assessment and Intervention. AFB Press, USA.

Sightsavers, 2012. Situational analysis of the education of children with visual impairments and other disabled children in Malawi. In: Unpublished Final Report. Sightsavers, UK.

Tumwesigye, C., Msukwa, G., Njuguna, M., Shilio, B., Courtright, P., Lewallen, S., 2009. Inappropriate enrollment of children in schools for the visually impaired in east Africa. Annu. Trop. Paediatrics 29 (2), 135-139.

UNICEF, 2008. Child-Friendly Schools: Emerging Practice in Eastern and Southern Africa. A Human Rights-Based Approach. United Nations Children's Fund, Nairobi, Kenya.

Yahalom, C., Tzur, V., Blumenfeld, A., Greifner, G., Dalia, E., Rosenmann, A., Glanzer, S., Anteby, I., 2012. Refractive profile in oculocutaneous albinism and its correlation with final visual outcome. Br. J. Ophthalmol. 96 (4), 537-539. 